\title{
Laboratory Scale Investigation to Improve the Productivity of Stamp Charge Coke Oven through Optimisation of Bulk Density of Coal Cake
}

\author{
P. S. DASH, S. H. KRISHNAN, R. SHARMA, P. K. BANERJEE and S. K. HALDAR ${ }^{11}$
}

Raw Materials and Cokemaking Research Group, Research and Development, Tata Steel, P.O.: Burmamines, Jamshedpur831007, Jharkhand, India. E-mail: pratikswarupdash@tatasteel.com; shkrishnan@tatasteel.com; rsharma@tatasteel.com; pkbanerjee@tatasteel.com

1) Coke Plant, Tata Steel, Jamshedpur-831001, Jharkhand, India.

E-mail: skhaldar@tatasteel.com

(Received on April 26, 2005; accepted on August 2, 2005)

\begin{abstract}
In the recent past, it was realised that the gross coke yield was going down as a result of lower oven throughput in the stamp charged batteries of Tata Steel. The basic reason for this being the net reduction in the ash content of the coal blend used due to the incorporation of higher percentage of low ash imported coals and reduction in the ash content of captive coals through washing. The coals having higher ash content improves the bulk density, as the specific gravity of ash is higher than that of pure coal. Moreover, the ash components have affinity for water and pure coal repels water, which in case of pure coal, works against the holding together of the blend. Hence, lower the ash content, less is the bulk density of cake under identical stamping energy and lower the bulk density, less is the oven throughput. In order to maximise the oven throughput and productivity, a study was conducted in the laboratory mainly to assess the effect of various blend constituents and their ash content on the bulk density of coal charge. The effect of ash content on the coal cake stability has also been dealt with. This study, in short, is a useful tool for selecting the right type of coals and designing the optimum blend for stamp charging to achieve maximum throughput and productivity.

In addition, studies were also carried out to assess the effect of addition of various binders on coal cake stability at lower moisture level which would also help in achieving higher throughput and productivity.
\end{abstract}

KEY WORDS: bulk density; coal cake stability; stamp charging; stamping energy; H.G.I.; compressive strength; shear strength; specific gravity; ash; volatile matter.

\section{Introduction}

Successful and sustainable implementation of Stamp Charging Technology in Tata Steel has given it an edge over conventional Top Charging Technology in terms of production of superior quality of Blast Furnace grade coke from a wide range of coal base, even permitting use of inferior coals. To derive the maximum benefit from this technology it is important to achieve the requisite dry bulk density and stability of the stamped coal cake. It was noticed that with the increase in the percentage of imported Semi-soft component in the blend the bulk density of the coal cake started declining. With the introduction of captive coals washed to a lower ash level, the bulk density further declined. Such decline in the bulk density of coal cake has resulted in lowering of oven throughput and hence the productivity. The productivity is also affected significantly with the higher moisture content in the coal blend. Application of suitable binders in the coal blend may perhaps ensure better coal cake stability at a lower moisture level and would contribute to enhancing the productivity. So, in order to maximise the oven throughput and in turn the productivity, a study was undertaken in the laboratary to evaluate the effect of various blend constituents and their ash content on the bulk density of coal charge as well as to select a suitable alternative binder for use in making the stamped coal cake.

The research work carried out earlier in R\&D, Tata Steel in this area had revealed that the stamping energy, the moisture content and granulometry of coal blend are the three main factors which control the strength and density of stamped coal cake. ${ }^{1-4)}$ The following were the findings:

- The bulk density decreases from 1195 to $1145 \mathrm{~kg} / \mathrm{m}^{3}$ with an increase in crushing fineness from 80 to $90 \%$. Increase in crushing fineness $(-3.2 \mathrm{~mm})$ beyond $90 \%$, affects the density marginally; in other words, the bulk density is higher for coarser coal.

- As the amount of -0.5 fraction increases from 20 to $70 \%$ the BD decreases from 1190 to $1120 \mathrm{~kg} / \mathrm{m}^{3}$. This further confirms that the bulk density of coal cake is higher for coarser crushing.

- With an increase in moisture content from 6.2 to $12.6 \%$, the dry BD increases by $3.2 \%$ whereas, the wet bulk density increases to the extent of $5.8 \%$.

- Coal cake with the desired strength can be produced by maintaining a crushing fineness (below $3.2 \mathrm{~mm}$ ) of around $90 \%$, moisture content at $9-10 \%$ and stamping 
energy at around $450 \mathrm{Nm} / \mathrm{kg}$.

The earlier work did not include the studies on the effect of ash content of the coal blend. The coals having higher ash content improves the bulk density, as the specific gravity of ash is higher than that of pure coal. Moreover, the ash components have affinity for water and pure coal repels water, which in case of pure coal, works against the holding together of the blend. Hence, lower the ash content, lower is the bulk density of the coal cake under identical stamping energy, moisture content and crushing fineness.

Compared to the conventional top charging, stamp charging is a more energy intensive process as the extra quantity of water (3-4\%), added intentionally to the coal blend to impart the requisite cake strength, calls for additional thermal energy and also causes delay in the process. Besides, the extra water prohibits that much amount of coal from being charged into the oven. Hence, another alternative for increasing the productivity of stamp charged batteries may be brought about through addition of a suitable organic binder to the coal charge.

Addition of organic binders like tar and pitch to the coal blend, ${ }^{5)}$ prior to stamping is expected to reduce the consumption of thermal energy, improve the productivity and would impart the requisite strength and stability at lower moisture levels. Moreover, tar and pitch addition improves the strength characteristics of the resultant coke made from coals having poor rheological properties. In the mid-twenties H. Brosche, ${ }^{6}$ ) extracted so called coal bitumen from high grade coking coal and showed that, when the extracted bitumen coal added to a low-rank coal type, it proved possible to produce usable blast furnace coke. These experiments were the basis for later technical purposes to produce coke from low rank coal by the addition of binders. Since then, different types of additives have been tried to alter the basic coking propensity.

Coal tar and pitch are a resinous material containing $\alpha$ and $\beta$ types of resins. $\beta$ resins, indicated by the difference between Quinoline Insoluble (Q.I.) and Benzene/Toluene Insoluble (B.I./T.I.) contribute significantly to the binding of coal particles. ${ }^{7)}$

Moreover, the imported semi-soft coals, presently being used in the stamp charging coal blend in Tata Steel, although have low ash and low V.M., lack in rheological properties. Additives such as coal tar and pitch, ${ }^{8)}$ commonly referred to as fluidity enhancers, can play a more direct role in improving the strength characteristics of the resultant coke. ${ }^{9)}$ It is reported that addition of coal tar and pitch to coal blends improves the fluidity of the blends, favours wetting of non-softening grains, effects the homogenisation of coal mass and facilitates moving and binding of the structure elements. Tar and pitch penetrating into the porous structure of coal, retards the thermal decomposition of the group components of the blend at plastic temperatures and promotes the re-arrangements of the structure. Coal tar and pitch has an advantageous influence on the formation of homogeneous optically anisotropic coke structures with high mechanical strength. ${ }^{10)}$

There are numerous binders like coal tar, pitch, bentonite, sodium ligno sulphanate, latex, phenolic resins, molasses, sodium silicate etc. ${ }^{11)}$; but coal tar and pitch, being coal derivatives were selected for the trials. Most of the other binders do not help in improving the strength of the resultant coke, on the other hand add harmful constituents to the coal blend. Although elaborate studies in the laboratory as well as in the plant have been carried out earlier on the use of pitch as a part replacement of moisture as binder, ${ }^{12)}$ it could not be implemented on a continuous basis due to non-availability and higher cost of pitch. Hence, it was decided to replace pitch with alternative binders like coal tar.

\section{Experimental}

Considering the large size of the coke plant and the difficulties involved in closely controlling the operating parameters, it is practically not possible to carry out the requisite trials on a commercial scale. So, the following studies were carried out in the laboratory:

A. The effect of ash content on the bulk density of coal cake.

B. The effect of ash content and addition of binders on the stability of coal cake.

\subsection{The Effect of Ash Content on the Bulk Density of Coal Cake}

A unique $3-\mathrm{kg}$ compacting equipment was specifically designed and fabricated in house to determine the bulk density of coal cake at different stamping energy. The compacting unit is shown in Fig. 1. The dimension of the coal cake made in this unit reads as $101 \times 102 \times 260 \mathrm{~mm}$. The sliding weight $(20 \mathrm{~kg})$ is dropped on the ram from a height of 54 $\mathrm{cm}$. The coal was compacted by the drop hammer principle in accordance with operating parameters used in large scale stamping units. The kinetic energy required to accomplish ramming was converted from the potential energy of the rammer. The stamping energy imparted per unit weight of coal during cake making is referred to as the "specific stamping energy". The specific stamping energy was calculated from the number of drops of rammer and the bulk density of the coal cake was determined from the volume of the cake, by measuring its dimensions and its weight.
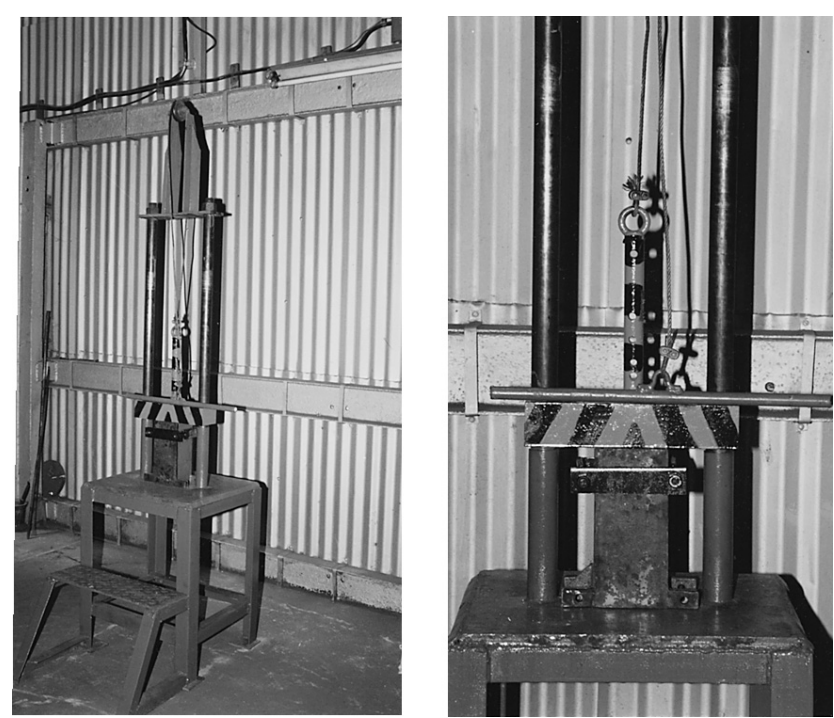

Fig. 1. Set up for determination of bulk density after compaction of coal charge. 
Table 1. Properties of individual coals.

\begin{tabular}{|c|c|c|c|c|c|c|c|}
\hline PARAMETERS & Coal A & Coal B & Coal C & Coal D & Coal E & Coal F & Coal G \\
\hline $\begin{array}{r}\text { Proximate Analysis (db), \% } \\
\text { Ash } \\
\text { VM } \\
\text { FC }\end{array}$ & $\begin{array}{l}16.1 \\
27.6 \\
56.3\end{array}$ & $\begin{array}{l}15.9 \\
22.9 \\
61.2\end{array}$ & $\begin{array}{l}16.9 \\
20.3 \\
62.8\end{array}$ & $\begin{array}{c}8.2 \\
20.8 \\
71\end{array}$ & $\begin{array}{c}9.8 \\
18.7 \\
71.5\end{array}$ & $\begin{array}{c}10.0 \\
7.6 \\
82.4\end{array}$ & $\begin{array}{c}9.1 \\
17.4 \\
73.5\end{array}$ \\
\hline Hardgroove Grindability Index (H.G.I.) & 75 & 82 & 95 & 95 & 94 & 82 & 87 \\
\hline Specific Gravity & 1.428 & 1.482 & 1.434 & 1.219 & 1.304 & 1.421 & 1.359 \\
\hline $\begin{array}{l}\text { Gieseler Fluidity Test. } \\
\text { Maximum Gieseler Fluidity, ddpm } \\
\text { Initial Softening Temperature }\left(\text { IST), }{ }^{\circ} \mathrm{C}\right. \\
\text { Resolidification Temperature, }{ }^{\circ} \mathrm{C}\end{array}$ & $\begin{array}{l}3310 \\
434 \\
506\end{array}$ & $\begin{array}{c}1364 \\
438 \\
511\end{array}$ & $\begin{array}{l}848 \\
445 \\
505\end{array}$ & $\begin{array}{c}5 \\
450 \\
484\end{array}$ & $\begin{array}{l}80 \\
466 \\
512\end{array}$ & $\begin{array}{l}0 \\
- \\
-\end{array}$ & $\begin{array}{l}0 \\
- \\
-\end{array}$ \\
\hline $\begin{array}{c}\text { Audibert - Arnu Dilatometry } \\
\text { Max. Contraction , \% } \\
\text { Max. Expansion , \% }\end{array}$ & $\begin{array}{l}26 \\
29\end{array}$ & $\begin{array}{l}26 \\
92\end{array}$ & $\begin{array}{l}21 \\
50\end{array}$ & $\begin{array}{l}20 \\
\text { Nil }\end{array}$ & $\begin{array}{l}24 \\
47\end{array}$ & - & $\begin{array}{c}8 \\
\text { Nil }\end{array}$ \\
\hline Crucible Swelling Number (CSN)/FSI & 4.0 & 6.5 & 7.5 & 3.5 & 8.5 & 0 & 1.5 \\
\hline Petrographic Analysis, \% & & & & & & & \\
\hline $\begin{array}{l}\text { Reactives } \\
\text { Inerts } \\
\text { Mean Max. Reflectance (MMR) }\end{array}$ & $\begin{array}{l}54.7 \\
45.3 \\
1.06\end{array}$ & $\begin{array}{l}50.6 \\
49.4 \\
1.22\end{array}$ & $\begin{array}{l}55.4 \\
44.6 \\
1.28\end{array}$ & $\begin{array}{l}49.8 \\
50.2 \\
1.14\end{array}$ & $\begin{array}{l}54.6 \\
43.4 \\
1.40\end{array}$ & $\begin{array}{l}54.2 \\
42.8 \\
2.05\end{array}$ & $\begin{array}{l}51.1 \\
48.9 \\
1.46\end{array}$ \\
\hline
\end{tabular}

\subsubsection{Bulk Density of Coal Cake with Individual Coals}

For carrying out the experiments in the laboratory, seven coals (three captive and four imported) mostly used in the coke plant at Tata Steel were selected. These coals include captive medium coking coal (Coal A), captive prime coking coals (Coal B and Coal C), imported Semi-soft coal (Coal D), imported hard coking coal (Coal E), Anthracite (Coal F) and imported low volatile matter (V.M.) coal (Coal $\mathrm{G})$. The proximate analysis, specific gravity, Hardgroove Grindability Index (H.G.I.), rheological and petrographic properties of these coals are depicted in Table 1.

The initial sets of tests were done for these individual coals at a fixed crushing fineness $(\sim 90 \%)$, and moisture content $(\sim 10 \%)$ (as being practiced in the coke plant at Tata Steel). The bulk densities that can be achieved at different stamping energy were determined for various individual coals. The stamping energy required for achieving the designed bulk density of $1150 \mathrm{~kg} / \mathrm{m}^{3}$, the maximum bulk density that can be achieved and the corresponding stamping energy of different coals were also evaluated.

\subsubsection{Bulk Density of Coal Cake with Blends}

The second sets of tests were done to study the effect of ash content on bulk density. After the analyses of the results obtained from bulk density evaluation tests with individual coals, coal blends were prepared at various ash levels by varying the proportions of Coal A and Coal D in the blends. The bulk densities of various coal blends at different stamping energies and the specific stamping energy required at various ash levels to achieve the designed bulk density of $1150 \mathrm{~kg} / \mathrm{m}^{3}$ were determined.

\subsubsection{Bulk Density of Coal Cake Using Blends Having Coal A Washed at Different Levels}

The ash content of the stamp charge coal blend has also been affected by the reduction of ash content in captive coals due to improved beneficiation. The ash levels of captive coals are expected to go down further to nearly $10 \%$ in future. With this in view, Coal A, one of the major captive coal component in the stamp charging blend was washed at various specific gravities using sink float test to generate coals at various ash levels. The washed coals thus produced were suitably blended to obtain Coal A having 10, 12, 14 and $16 \%$ ash contents. These coals were then used for the preparation of blends containing 50\% Coal A and 50\% Coal D and the same bulk density evaluation tests were conducted for each blend as explained earlier.

\subsection{The Effect of Ash Content and Addition of Binders on the Stability of Coal Cake}

Two different equipment were used for the determination of stability of coal cake. One for making test coal cake by ramming and the other for determining their compressive and shear strengths. ${ }^{12)}$

The coal was compacted by the drop hammer principle in accordance with the operating parameters followed in large scale stamping units. The coal cake was produced in a die into which the charge is fed and compacted with a rammer to a cylindrical shape of $50 \times 50 \mathrm{~mm}$. The kinetic energy required to accomplish ramming was converted from the potential energy of the rammer whose weight and height were adjusted. The test cake was made after determination of the number of drops required to produce cake with specified stamping energy. The coal cakes, thus made, were subjected to testing in the other equipment for the determination of compressive and shear strengths. For adequate stability of the coal cake, the minimum shear and compressive strength required are $1500 \mathrm{~kg} / \mathrm{m}^{2}$ and $16000 \mathrm{~kg} / \mathrm{m}^{2}$ respectively.

\subsubsection{Stability of Coal Cake With Blends}

The first series of tests were conducted to find out the compressive and shear strength of coal cakes made of 
Table 2. Analysis of coal tar and coal tar pitch used in the tests.

\begin{tabular}{|l|c|c|c|}
\hline \multicolumn{1}{|c|}{ Properties } & Pitch 1 (Old) & Pitch 2 (New) & Tar \\
\hline Inherent Moisture, \% & Nil & 1.10 & 1.70 \\
\hline Ash (db), \% & 0.20 & 0.50 & - \\
\hline V.M. (db), \% & 42.20 & 52.73 & - \\
\hline Total Alkalis $\left(\mathrm{Na}_{2} \mathrm{O}+\mathrm{K}_{2} \mathrm{O}\right), \%$ & 0.015 & 0.063 & - \\
\hline Sulphur, \% & 0.61 & 0.44 & - \\
\hline Phosphorus, \% & 0.035 & 0.002 & - \\
\hline Q. I. Content, \% & 4.96 & 13.84 & 1.50 \\
\hline T.I. Content, \% & 23.60 & 27.84 & 3.60 \\
\hline
\end{tabular}

blends prepared at various ash levels by varying the proportions of Coal A and Coal D in the blends at same level of stamping energy. The tests with these above blends were repeated later keeping the bulk density of the coal cake constant.

\subsubsection{Stability of Coal Cake Using Blends Having Coal A Washed at Different Levels}

The second series of tests were done to evaluate the coal cake stability of coal cakes made of blends having Coal A $(50 \%)$ and Coal D (50\%) where, Coal A having 10, 12, 14 and $16 \%$ were used. These tests were also done at same level of stamping energy and same bulk density as above.

\subsubsection{Stability of Coal Cake at Different Moisture Levels}

The third series of tests were conducted to find out the optimum level for the moisture content of the coal blend to achieve maximum possible strength and stability under the conditions being followed presently in the plant (without any binder addition).

\subsubsection{Stability of Coal Cake Using Different Binders}

Keeping these strength values as the base, a fourth series of trials were carried out to determine the compressive and shear strengths of the coal cakes made under different dosages of addition of various binders to the coal blend at two different levels of moisture contents $(7 \%$ and $8 \%)$. These moisture levels were chosen mainly because of the fact that the moisture contents of the as received coals in the coke plant remain at an average level of 7-8\% during non-monsoon seasons. During monsoon, the moisture is usually at a much higher level and addition of binder will neither be needed for improving the coal cake stability nor will be economical.

The coal blend used in all these tests composed of Coal B (10\%), Coal A (50\%) and Coal D (40\%). Three different binders were tried to have a comparative evaluation. First binder that was tried is coal tar from by-product plant of Tata Steel, second is hard pitch obtained as a derivative of tar distillation, which is being carried out by outside party using the coal tar generated at coke plant, Tata Steel (Pitch 1) and the third is another Pitch sample procured from outside party (Pitch 2). Pitch 1 is the same pitch sample which was used for the earlier study on application of binder in stamp charge coke making. ${ }^{12)}$ The properties of the tar and pitch samples used in all these tests are given in Table 2. The crushing fineness of coal and pitch samples used was maintained at $90 \pm 1 \%$ (through $0.0032 \mathrm{~m}$ ) and the wet bulk density of the coal cake remained between $1140-1160 \mathrm{~kg} / \mathrm{m}^{3}$. The test cakes were made after determination of the number of drops required to produce cake with specified stamping energy of about $450 \mathrm{Nm} / \mathrm{kg}$.

First the tests were conducted with different dosages of tar addition (0.25-6\%) at two different moisture levels (7\% and $8 \%$ ) to find out the maximum achievable coal cake strength and the optimum amount of tar addition required for adequate stability. Then the stability tests were done using Pitch 2 as a binder at different dosages $(0.5-4.0 \%)$ at $7 \%$ moisture level. At last for having a comparative evaluation, Pitch 1 was added to the coal blend at only one level ( $0.5 \%$ as recommended) at $7 \%$ moisture level as elaborate study has already been done at R\&D, Tata Steel using this binder earlier. ${ }^{12}$ The comparative evaluation of effect of different binders on coal cake stability has also been carried out in this study.

\section{Results and Discussion}

\subsection{The Effect of Ash Content on the Bulk Density of Coal}

3.1.1. Bulk Density of Coal cake With Individual Coals

- The stamping energy required for achieving the designed bulk density of $1150 \mathrm{~kg} / \mathrm{m}^{3}$, the maximum bulk density that can be achieved and the corresponding stamping energy for different coals are summarised in Table 3 . Figure 2 depicts the bulk density of various individual coals at different stamping energy.

- It is evident from Fig. 2 and Table 3; among all the individual coals tested, the captive Coal $\mathrm{C}$ requires the least energy for achieving the requisite bulk density of $1150 \mathrm{~kg} / \mathrm{m}^{3}$. In the order of increasing energy requirement, the rest of the coals may be placed as Coal F, Coal B, Coal G, Coal A, Coal E, Coal D. Coal D and Coal E are the most difficult coals to stamp and requires maximum stamping energy $(1200 \mathrm{Nm} / \mathrm{kg}$ and $1100 \mathrm{Nm} / \mathrm{kg}$ respectively) for achieving designed bulk density of $1150 \mathrm{~kg} / \mathrm{m}^{3}$. With these coals, the maximum bulk density that can be achieved is only $1156 \mathrm{~kg} / \mathrm{m}^{3}$ and $1206 \mathrm{~kg} / \mathrm{m}^{3}$ respectively and even application stamping energy beyond this level does not improve the bulk density. It is possible to achieve designed bulk density by applying less then $500 \mathrm{Nm} / \mathrm{kg}$ stamping energy with the captive coals (Coal A, Coal B and Coal C), Coal F and Coal G. The maximum bulk density $\left(1312 \mathrm{~kg} / \mathrm{m}^{3}\right)$ was obtained 
Table 3. Bulk density of coal cake and corresponding stamping energy of individual coals.

\begin{tabular}{|c|c|c|c|}
\hline Coals & $\begin{array}{l}\text { Stamping Energy }(\mathrm{Nm} / \mathrm{kg}) \\
\text { for achieving } 1150 \mathrm{~kg} / \mathrm{m}^{3} \mathrm{BD}\end{array}$ & $\begin{array}{l}\text { Maximum Bulk } \\
\text { Density, } \mathrm{kg} / \mathrm{m}^{3}\end{array}$ & $\begin{array}{c}\text { Stamping Energy }(\mathrm{Nm} / \mathrm{kg}) \text { for } \\
\text { maximum } \mathrm{BD}\end{array}$ \\
\hline Coal A & 475 & 1257 & 1950 \\
\hline Coal B & 435 & 1290 & 2480 \\
\hline Coal C & 315 & 1312 & 2170 \\
\hline Coal D & 1200 & 1156 & 1320 \\
\hline Coal E & 1100 & 1206 & 2325 \\
\hline Coal F & 425 & 1286 & 2170 \\
\hline Coal G & 450 & 1257 & 1860 \\
\hline
\end{tabular}

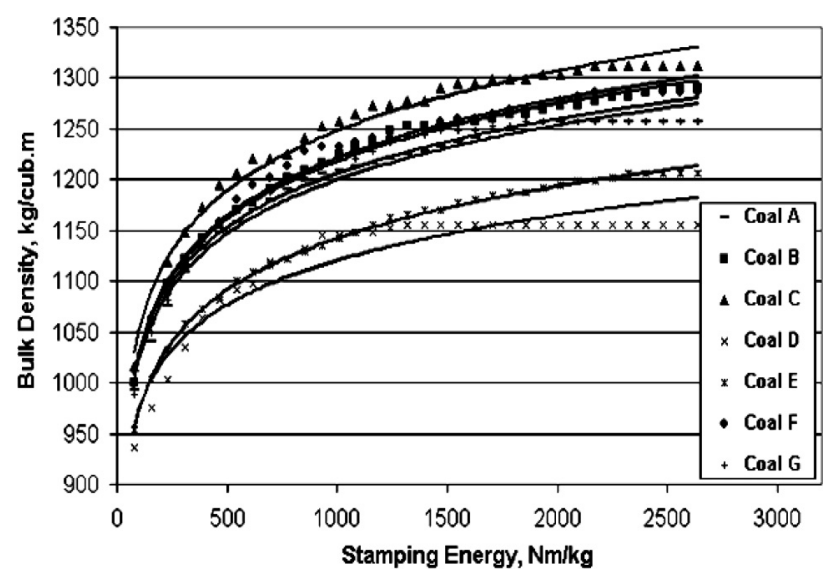

Fig. 2. Bulk density of coal cake for individual coals at different stamping energies.

with Coal $\mathrm{C}$ at the energy level of $2170 \mathrm{Nm} / \mathrm{kg}$.

- At a fixed crushing fineness and moisture content, ash content, fixed carbon content, volatile matter, H.G.I. and specific gravity are the parameters that influence the bulk density the most. Hence, different correlations have been developed for determining bulk density $\left(\mathrm{kg} / \mathrm{m}^{3}\right)$ of coal cake taking stamping energy (SE) $(\mathrm{Nm} / \mathrm{kg})$, ash (db) (\%), V.M. (db) (\%), H.G.I. and specific gravity as the independent variables. A few correlations are given below:

1. Bulk Density $=1088.3+11.0 *($ Ash $)-4.3 *($ V.M. $), R^{2}=$ 0.71

2. Bulk Density $=1136.5+10.6 *($ Ash $)-4.3 *($ V.M. $)-0.5 *$ (H.G.I.), $R^{2}=0.72$

3. Bulk Density $=558.2+2.65 *($ Ash $)-1.56 *($ V.M. $)-$ $0.99 *($ H.G.I. $)+357.65 *($ Sp. Gravity $), R^{2}=0.77$

4. Bulk Density $=828.0+5.5 *($ Ash $)-2.6 *$ (V.M. $)+$ $213.9 *\left(\right.$ Sp. Gravity), $R^{2}=0.75$

5. Bulk Density $=1044.62+0.075 *(\mathrm{SE})+12.76 *($ Ash $)-$ $5.44 *$ (V.M.), $R^{2}=0.75$

6. Bulk Density $=1120.68+0.075^{*}(\mathrm{SE})+12.09 *($ Ash $)-$ 5.36* (V.M.) $-0.80 *$ (H.G.I.), $R^{2}=0.76$

7. Bulk Density $=673.61+0.075 *(\mathrm{SE})+4.93 *(\mathrm{Ash})-$ $3.0 *$ (V.M.) $+304.84 *\left(\right.$ Sp. Gravity), $R^{2}=0.77$

Ranges of various properties considered in the above correlations:

Ash (db), \%: 8.2-16.9

V.M. (db), \%: 7.6-27.6

H.G.I.: 75-95

Specific Gravity: 1.219-1.482

The correlations are applicable within the ranges of various properties shown above. These correlations are ob-

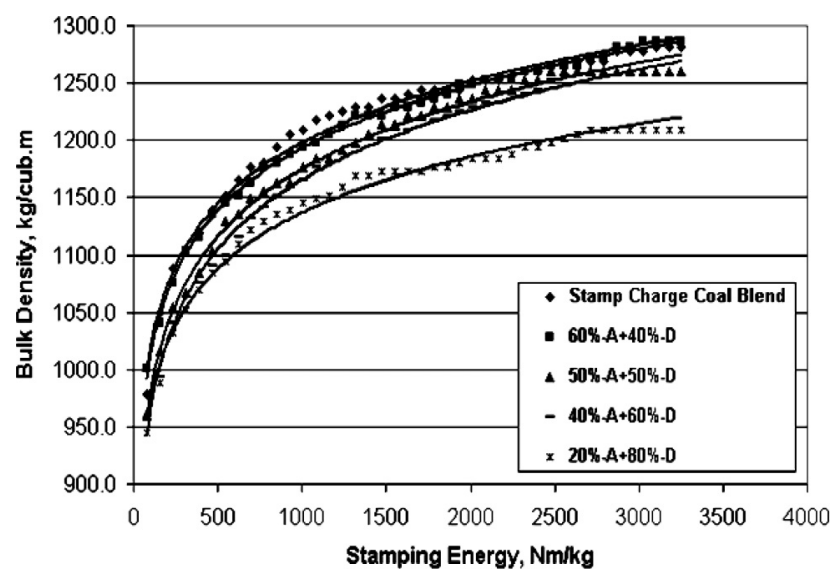

Fig. 3. Bulk density of coal cake for coal blends at different stamping energies.

tained by using only seven coals. Clearly further research work is necessary on the applicability of these equations to different coal blends. However, the above correlations clearly indicate the positive effect of ash content and the negative effect of V.M. content with respect to the bulk density. Also, higher the specific gravity and lower the H.G.I., higher would be the bulk density. Since the captive coals have higher ash content, the bulk density of the coal cake made with these coals have higher bulk density. All the captive coals, though almost identical in ash content, the Coal $\mathrm{C}$ gives the highest bulk density due to its low V.M. content. Although all the imported coals have low ash compared to captive coals, Coal F and Coal G figure better than those of Coal D and Coal E, as there V.M. contents are much lower. Higher the value of H.G.I., more soft and light is the coal. Hence, the bulk density of the coal charge decreases with increase in value of H.G.I.

From these tests results, it can be easily interpreted that Coal A, Coal B, Coal C, Coal F and Coal G which requires nearly the same stamping energy for achieving the designed bulk density can be put in one category and Coal D and Coal $\mathrm{E}$ in the other category. This analysis formed the basis for subsequent tests done for bulk density evaluation using coal blends.

\subsubsection{Bulk Density of Coal Cake with Blends}

- The bulk densities of various coal blends (made by varying the proportions of Coal A and Coal D in the blend) at different stamping energies are plotted in Fig. 3. The findings from the study showing bulk density of stamped coal cake at different ash levels using identical 
specific stamping energy are depicted in Fig. 4. The specific stamping energy required at various ash levels to achieve the designed bulk density of $1150 \mathrm{~kg} / \mathrm{m}^{3}$ is shown in Table 4 and Fig. 5.

- The test results clearly suggest that the ash content of the stamp charging blend does influence the bulk density of stamped cake. Lower the ash content, lower is the bulk density of cake under identical stamping energy as can be seen from Figs. 3 and 4 . The stamping energy requiredfor achieving the designed bulk density of $1150 \mathrm{~kg} / \mathrm{m}^{3}$ of coal cake also increases as the blend ash level decreases as can be clearly observed from Fig. 5 and Table 4. Meaning thereby, increasing the proportion of Coal D in the binary blend with Coal A would call for additional energy application to maintain the same bulk density.

- Tor the blend (Coal A, 47\%; Coal B or Coal C, $8 \%$; Coal D, $30 \%$; Coal E, $8 \%$; Coal F or Coal G, 7\%) presently being used in stamp charging, the specific stamping ener-

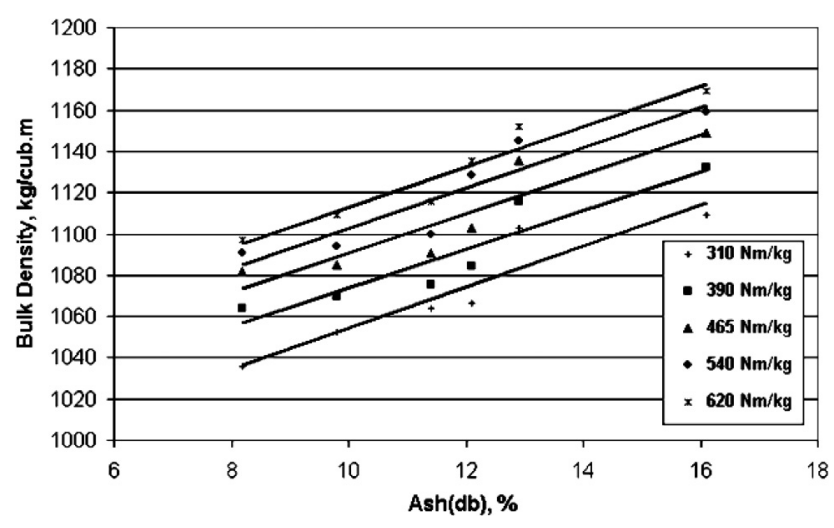

Fig. 4. Bulk density of coal cake vs. blend ash at a constant stamping energy.

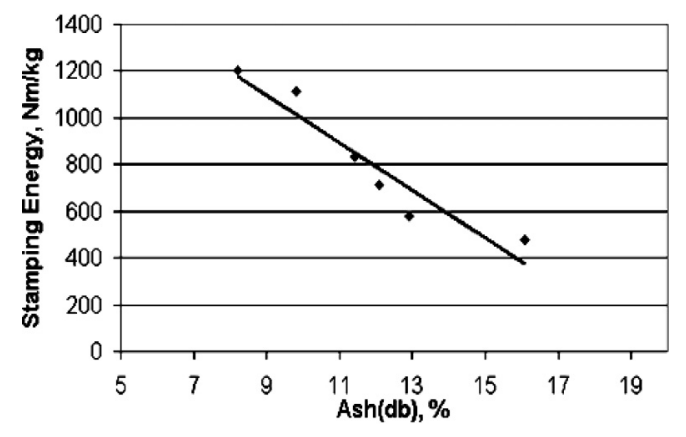

Fig. 5. Stamping energy required to achieve $1150 \mathrm{~kg} / \mathrm{m}^{3}$ bulk density of coal cake at various blend ash levels. gy required to achieve the designed bulk density is $530 \mathrm{Nm} / \mathrm{kg}$. The bulk density vs. specific stamping energy curves for the above blend is almost overlapping with the $60 \%$ Coal A and $40 \%$ Coal D blend as expected. The stamp charging blend mentioned above contains $62 \%$ of the kind of coals (Coal A, Coal B, Coal C, Coal F and Coal G) which can be stamped with lesser energy. Hence, for decrease of ash level in the stamp charging blend, more specific stamping energy has to be applied to maintain the bulk density.

3.1.3. Bulk Density of Coal Cake Using Blends Having Coal A Washed at Different Levels

- The bulk densities of the coal blends (blends prepared with 50\% Coal A and 50\% Coal D) containing Coal A at different ash levels, at different stamping energies are plotted in Fig. 6. The specific stamping energy required for these blends at various ash levels of Coal A to achieve the designed bulk density of $1150 \mathrm{~kg} / \mathrm{m}^{3}$ is shown in Table 5.

- The same phenomena of dependence of bulk density on ash content can be observed in the case of the blends made with different ash levels of Coal A (Fig. 6). The specific stamping energy required to achieve designed bulk density increases, as expected, with decrease in ash levels of Coal A as can be seen from Table 5.

\subsection{The Effect of Ash Content and Addition of} Binders on the Stability of Coal Cxake

3.2.1. Stability of Coal Cake with Different Blends and Using Blends Having Coal A Washed at Different Ash Levels

- The compressive and shear strength of coal cakes, made

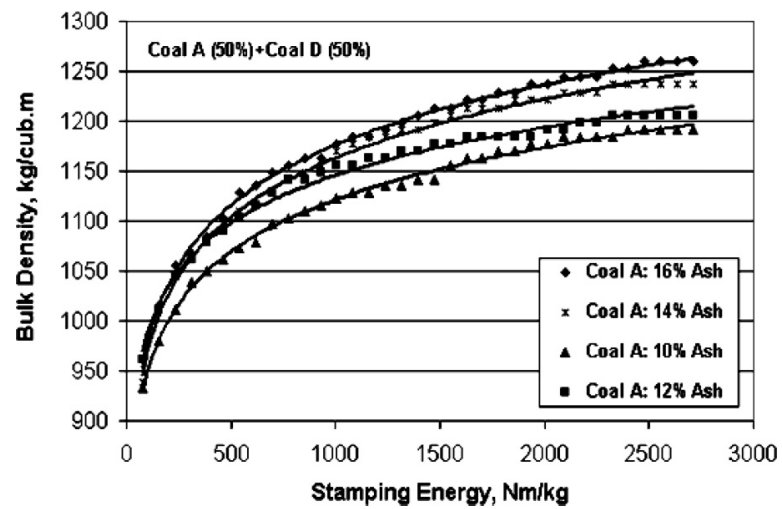

Fig. 6. Bulk density of coal cake and corresponding stamping energy of coal blends having Coal A of various ash contents.

Table 4. Bulk density of coal cake and corresponding stamping energy of coal blends.

\begin{tabular}{|c|c|c|c|}
\hline Coals & Ash (db), \% & VM (db), \% & $\begin{array}{c}\text { Stamping Energy (Nm/kg) } \\
\text { for achieving } 1150 ~ \mathbf{~ k g} / \mathbf{m}^{3} \text { BD }\end{array}$ \\
\hline Stamp Charge (S.C.) Coal Blend & - & - & 530 \\
\hline $60 \%$ A + 40 \% D & 12.9 & 24.9 & 580 \\
\hline $50 \%$ A + 50 \% D & 12.1 & 24.2 & 710 \\
\hline $40 \%$ A + 60 \% D & 11.4 & 23.5 & 835 \\
\hline $20 \%$ A + 80 \% D & 9.8 & 22.2 & 1115 \\
\hline
\end{tabular}


Table 5. Bulk density of coal cake and corresponding stamping energy of coal blends having Coal A of various ash contents.

Blend Composition: Coal A - 50

Coal D - 50

\begin{tabular}{|c|c|c|c|}
\hline $\begin{array}{c}\text { Ash (db) in } \\
\text { Coal A, \% }\end{array}$ & $\begin{array}{c}\text { Blend } \\
\text { Ash (db), \% }\end{array}$ & $\begin{array}{c}\text { Blend } \\
\text { VM (db), \% }\end{array}$ & $\begin{array}{c}\text { Stamping Energy (Nm/kg) } \\
\text { for achieving 1150 } \mathbf{~ k g} / \mathbf{m}^{3} \mathbf{B D}\end{array}$ \\
\hline 10 & 8.8 & 26.6 & 1515 \\
\hline 12 & 10.1 & 26.1 & 850 \\
\hline 14 & 11.2 & 25.3 & 710 \\
\hline 16 & 12.1 & 24.2 & \\
\hline
\end{tabular}
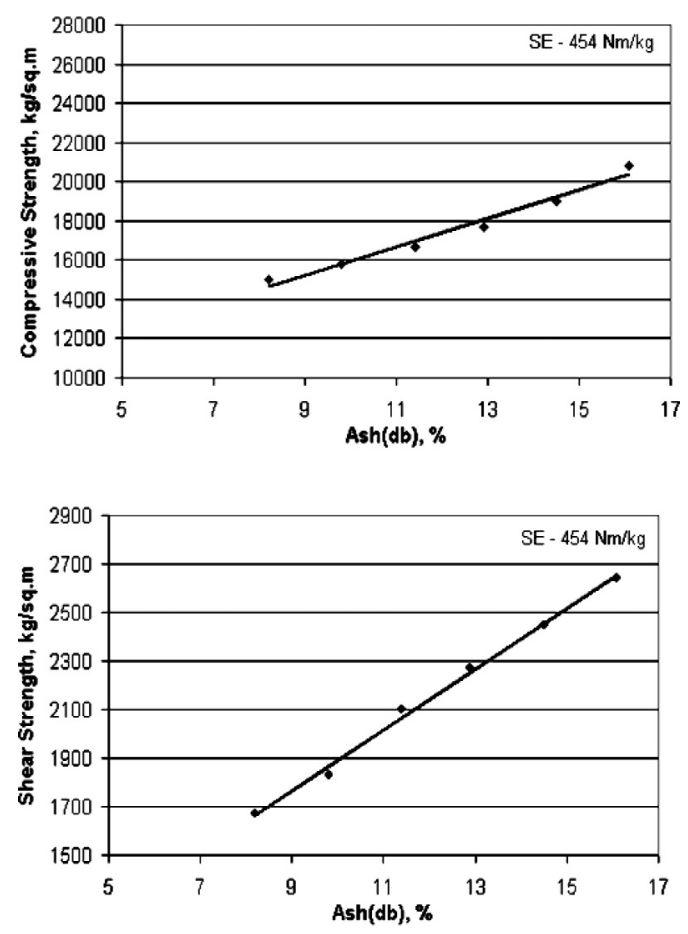

Fig. 7. Compressive and shear strength of coal cakes made of coal blends of various ash contents at same stamping energy.

of blends prepared at various ash levels by varying the proportions of Coal A and Coal D in the blends at same level of stamping energy, are depicted in Fig. 7. The test results with the above blends while keeping the bulk densities of the coal cakes constant are shown in Fig. 8. Figures 9 and $\mathbf{1 0}$ depicts the compressive and shear strength of coal cakes at same level of stamping energy and bulk density respectively, where the cakes are made of blends containing Coal D (50\%) and Coal A (50\%) having 10, 12, 14 and $16 \%$ ash contents.

- In Fig. 7, where ash content in the blend has been varied by varying the proportions of Coal $\mathrm{A}$ and Coal $\mathrm{D}$ and in Fig. 9, where ash variation has been achieved as a results of decrease in ash content of Coal A, it is clear that lower ash content of blend results in lowering compressive and shear strength of cake under identical stamping energy. The coal cake stability tests were repeated for all the blends, keeping the bulk density the same at $1146 \mathrm{~kg} / \mathrm{m}^{3}$. From the results, as can be seen in Figs. 8 and 10, it is clear that improvement in compressive and shear strengths
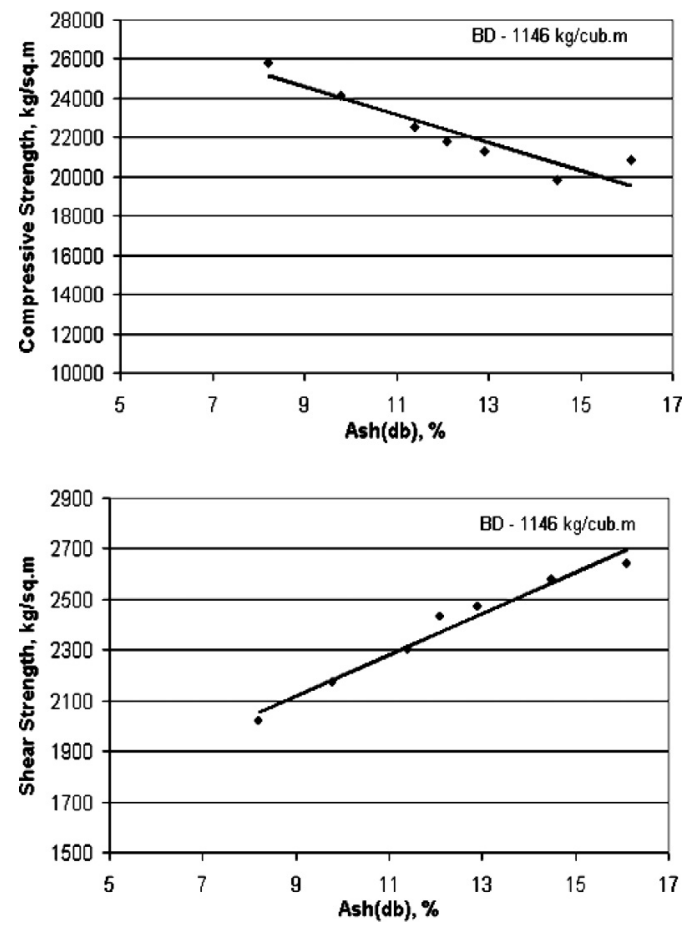

Fig. 8. Compressive and shear strength of coal cakes made of coal blends of various ash contents at same bulk density.

may be brought about by increasing the stamping energy. When the coal cake bulk density has been kept at constant level with decreasing ash level of the coal blend, the compressive strength has improved whereas shear strength shows a decreasing trend. However, the lowest values of shear strengths in these cases are above the desired limit of $1500 \mathrm{~kg} / \mathrm{m}^{2}$.

3.2.2. Stability of Coal Cake at Different Moisture Levels

- The laboratory experimental results for determining the optimum level of moisture content in the coal blend to achieve maximum possible strength and stability under the conditions being practiced in the plant (without any binder addition) are depicted in Fig. 11. At constant specific stamping energy, the stamping density increases as the moisture content increases. This is due to closer packing of the coal particles, creating a stronger interparticle surface interaction force. This leads to improvement in compressive and shear strength of the stamped coal cake up to a threshold limit as observed in Fig. 11. With further increase in the moisture level, the strength 

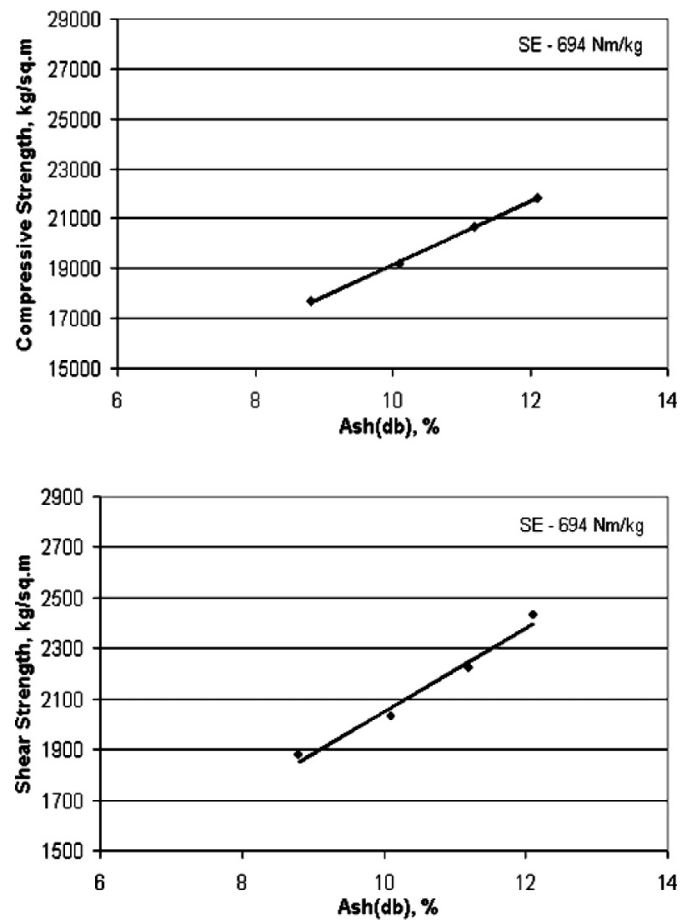

Fig. 9. Compressive and shear strength of coal cakes made of coal blends having Coal $\mathrm{A}$ of various ash contents at same stamping energy.
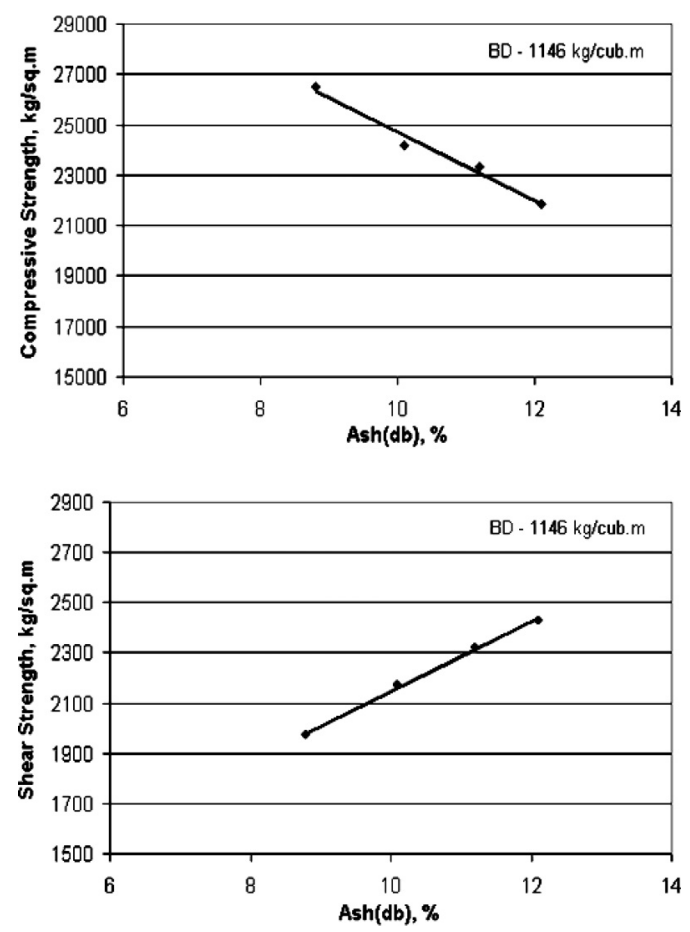

Fig. 10. Compressive and shear strength of coal cakes made of coal blends having Coal A of various ash contents at same bulk density.

of the coal cake deteriorates. This may be explained due to the fact that the presence of excess moisture inside the pores and in between particles prevents the formation of surface forces of interaction between particles leading to deterioration in strength of the coal cakes. Therefore, there exists an optimum moisture level where the positive effect of increasing moisture is the maximum. From Fig. 11 , it is obvious that maximum coal cake strength (both compressive and shear strength) could be achieved at
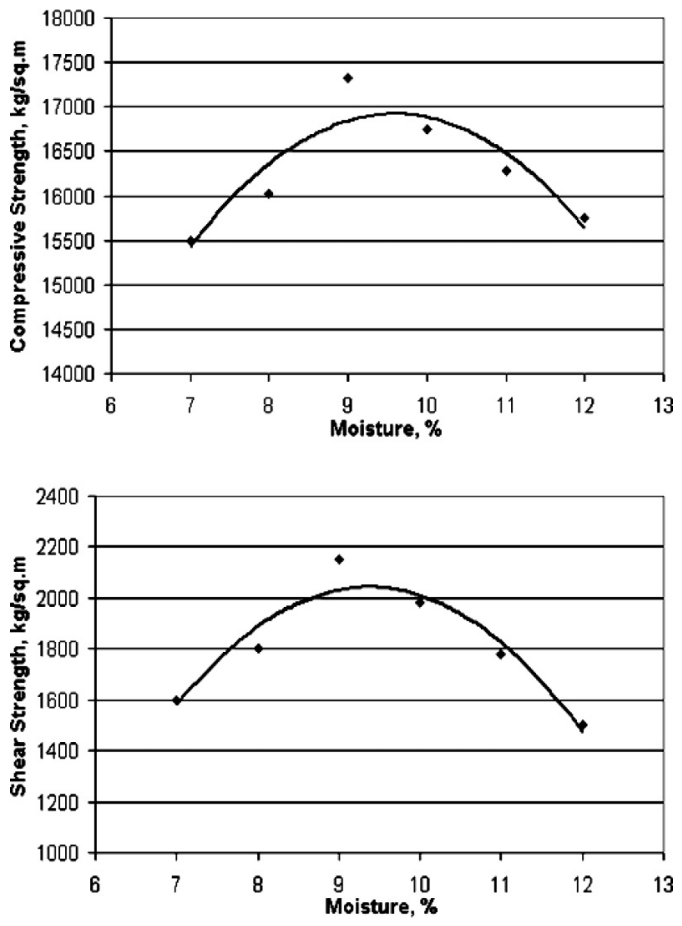

Fig. 11. Effect of moisture on the strength of coal cake.

around 9\% moisture level, without any binder addition. Although it is reported that the requisite coal cake strength is made of $9 \%$ moisture coal in the previous paper, ${ }^{12)} 10 \%$ was taken as the basis in this paper since the commercial plant maximum coal cake strength is obtained at a moisture level of $10 \%$.

\subsubsection{Stability of Coal Cake Using Different Binders}

- The laboratory test results of coal cake strength at different levels of tar addition (0.25-6.0\%) at 7\% and $8 \%$ moisture levels are represented in Fig. 12. In all these tests, the coal blends used were of identical crushing fineness. The bulk density was maintained within a close range of $1150 \pm 10 \mathrm{~kg} / \mathrm{m}^{3}$. Figure 12 shows an improvement in compressive and shear strengths of the coal cakes made under different dosages of tar addition up to nearly $3.5 \%$ for both the levels of moisture contents $(7 \%$ and $8 \%$ ). It is possible to get the requisite coal cake strength (as that of coal cake made of $10 \%$ moisture and without binder) even at lower moisture levels of $7 \%$ and $8 \%$ with only $2.0 \%$ and $1.25 \%$ tar addition respectively. Tar addition up to the extent of $2.0 \%$ and $3.5 \%$ to the coal blend is required at $8 \%$ and $7 \%$ moisture level respectively for achieving the maximum strength that is obtained at nearly $9 \%$ moisture level.

- Figures 13 and 14 represents the test results of coal cake strength at different level of moisture with lower and higher dosage of pitch 2 addition. Lower $(0.5 \%)$ dosage of Pitch 2 was added to the coal blend at $7 \%$ and $9 \%$ moisture levels whereas higher (1.0-4.0\%) dosages of pitch 2 were tried only at $7 \%$ moisture level. The requisite coal cake strength (as that of coal cake made of $10 \%$ moisture, without binder) could be achieved at lower moisture level (7\%) with only $1.0 \%$ of Pitch 2 addition. However, for achieving the strength that is obtained at around $9 \%$ moisture level, nearly $1.5 \%$ Pitch 

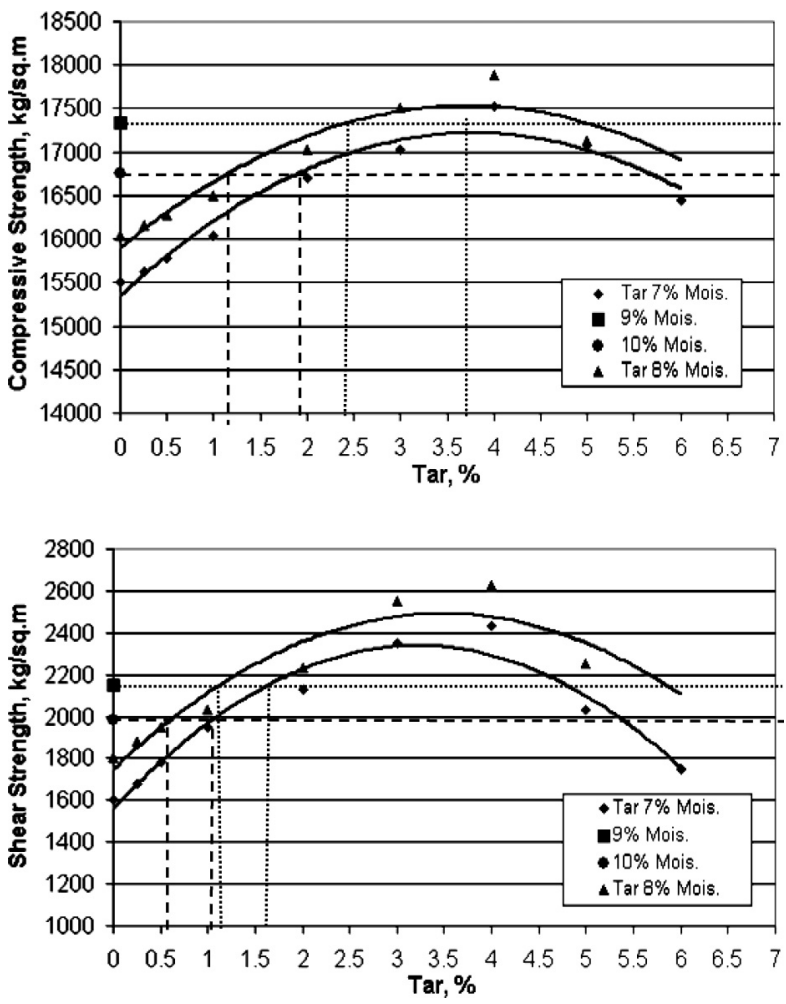

Fig. 12. Effect of tar addition on the strength of coal cake at different moisture levels.
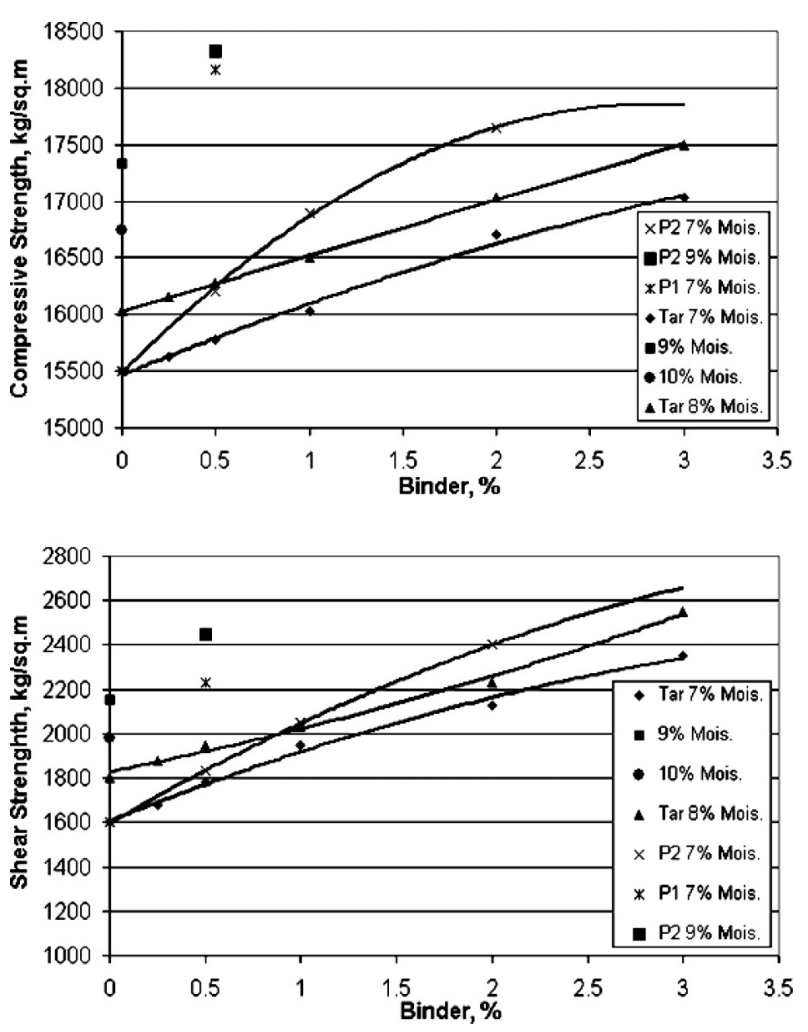

Fig. 13. Effect of addition of different binder addition on the strength of coal cake at different moisture levels.

2 addition to the coal blend is required at $7 \%$ moisture.

- Only one trial was done with $0.5 \%$ addition of pitch 1 as recommended earlier to have a comparison of the performance of different binders. It was observed that the coal cake strength was the highest with $0.5 \%$ addition of pitch
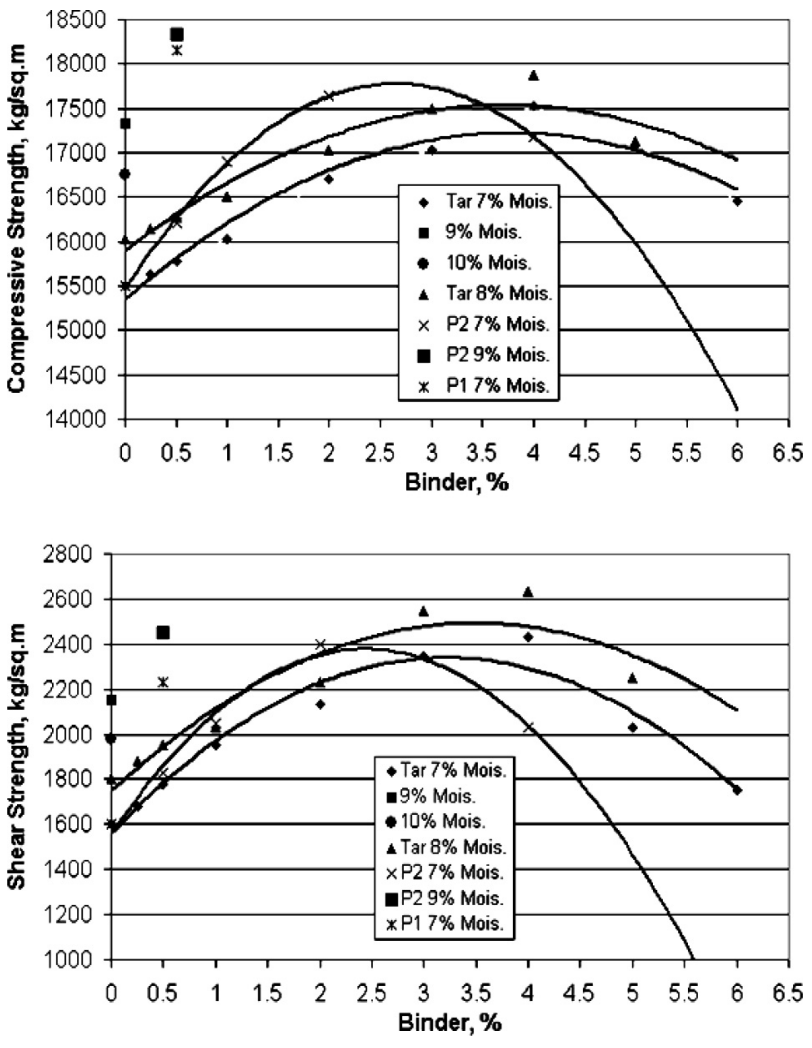

Fig. 14. Effect of addition of different binder addition on the strength of coal cake at different moisture levels.

1 at $7 \%$ moisture level compared to coal tar and Pitch 2 . The better binding effect of Pitch 1 is mainly due to its high $\beta$ resin content compared to the other two.

- The improvement in coal cake strength by tar or pitch addition is limited up to a certain percentage of tar and Pitch addition. Beyond this, the excess amount of tar or pitch in between particles causes the particle interfaces to slip across each other, and hence the stability of coal cake is affected adversely. As can be seen from Figs. 12 and 13, tar addition up to a level of nearly $4 \%$ and Pitch 2 addition up to a level of about $2.5 \%$, help improving the coal cake strength at $7 \%$ moisture level. Further addition of tar and pitch deteriorates its strength.

\section{Conclusion and Recommendation}

(1) With the present stamp charging blend comprising of captive medium coking Coal A (ash 16.1\%, V.M. $27.6 \%$ ), $47 \%$; captive prime coking Coal B (ash 15.9\%, V.M. $22.9 \%$ ) or captive prime coking Coal C (ash $16.9 \%$, V.M. $20.3 \%$ ), $8 \%$; imported semi-soft Coal D (ash $8.2 \%$, V.M. $20.8 \%$ ), $30 \%$; imported hard coking Coal E (ash $9.8 \%$, V.M. $18.7 \%$ ), $8 \%$; anthracite Coal $\mathrm{F}$ (ash $10.0 \%$, V.M. 7.6\%) or imported low V.M. Coal G (ash 9.1\%, V.M. $17.4 \%$ ), $7 \%$; a stamping energy of nearly $530 \mathrm{Nm} / \mathrm{kg}$ should be applied to achieve the desired bulk density of $1150 \mathrm{~kg} / \mathrm{m}^{3}$.

(2) In order to enhance productivity, stamp charging coal blend may be suitably designed incorporating more of high ash captive medium coking (Coal A) and captive prime coking coals (Coal B and C) and low V.M. coals like anthracite (Coal F) and Coal G taking into account the limi- 
tations on coke ash, cost of coal blend, safety of the oven.

(3) The requisite coal cake strength (as that of coal cake made of $10 \%$ moisture, without binder) could be achieved at lower moisture level of $7 \%$ and $8 \%$ with only $2.0 \%$ and $1.25 \%$ tar addition respectively.

(4) For achieving the maximum strength that is obtained at around 9\% moisture level, nearly $2.0 \%$ and $3.5 \%$ tar addition to the coal blend is required at $7 \%$ and $8 \%$ moisture level respectively.

(5) Regular monitoring and control of moisture content, crushing fineness and mean grain size should be practiced in order to maintain the optimum bulk density.

\section{REFERENCES}

1) B. K. Singh, K. C. Banerjee and A. S. Dhillon: Monograph on Stamp Charging Technology at Tata Steel, ed. by. B. K. Singh and H. N. Prasad, (1999), 11
2) M. Tiwari and P. V. T. Rao: Trans. Ind. Inst. Met., 46 (1993), No. 13, 127.

3) P. V. T. Rao and A. Chatterjee: Tata Search, 1 (1994), 27.

4) M. Tiwari, H. N. Prasad and B. K. Singh: Monograph on Stamp Charging Technology at Tata Steel, ed. by. B. K. Singh and H. N. Prasad, (1999), 84.

5) P. F. Gurtovnik, Yu. A. Larionov, I. I. Lipchik, V. K. Malevich, M. I. Bychev, V. I. Zhuravlev, D. S. Zvegilskii and I. A. Turik: Coke Chem., 7 (1982), 24.

6) H. Brosche, F. Fischer and J. Strauch: Brennst. Chem., 6 (1925), 33.

7) W. Kandler and W. Lakata: Cokemaking Int., 1 (1990), 67.

8) A. Chatterjee and H. N. Prasad: Fuel, 62 (1983), 591.

9) H. Spengler, W. Weskamp and G. Collin: Cokemaking Int., 3 (1991), No. 1, 25.

10) B. Bujnowska and G. Collin: Cokemaking Int., 6 (1994), 25.

11) M. Kitamura, H. Iwakiri, T. Kamijo and K. Narita: 41st Ironmaking Conf. Proc., ISS, Warrendale, PA, (1982), 424.

12) S. H. Krishnan, P. S. Dash, M. Guha, D. Kumar and D. P. Deshpande: ISIJ Int., 44 (2004), No. 7, 1150. 